\title{
Perdas de Forragem em Capim-Tanzânia (Panicum maximum Jacq cv. Tanzania-1) Manejado sob Diferentes Alturas sob Pastejo
}

\section{Ulysses Cecato ${ }^{1}$, Christian Roberto de Carvalho Castro ${ }^{2}$, Marcos Weber do Canto ${ }^{3}$, Maurício Peternelli², Josmar Almeida Júnior ${ }^{4}$, Clóves Cabreira Jobim¹, Clovenilson Claudio Perissato Cano ${ }^{2}$}

\begin{abstract}
RESUMO - O experimento foi conduzido com objetivo de avaliar as perdas de forragem e a acumulação de liteira em uma pastagem de capim-Tanzânia (Panicum maximum Jacq cv. Tanzania-1) manejada sob diferentes alturas. Os níveis de altura (tratamentos) estudados foram: 29,$8 ; 32,0 ; 47,1 ; 51,5 ; 57,9 ; 62,7 ; 72,6$ e 80,0 cm, em um delineamento completamente casualizado e com duas repetições. As taxas de acúmulo e acumulação de liteira e as perdas de forragem foram iguais em todas as alturas. A porcentagem de forragem senescente foi influenciada de forma quadrática pelos níveis de altura. Os resultados indicam que foram altos os níveis de acumulação de liteira e as perdas de forragem, em média, 38,9 kg/ha/dia de MS e $2179 \mathrm{~kg} / \mathrm{ha}$ de MS, respectivamente. Devido à possibilidade de se reduzirem a persistência da pastagem e a modificação da estrutura das plantas, recomenda-se não utilizar pastagens de capim-Tanzânia em alturas próximas ou iguais a 20 e $80 \mathrm{~cm}$, sob lotações contínuas.
\end{abstract}

Palavras-chave: forragem senescente, liteira, lotações contínuas, solo descoberto

\section{Forage Losses in Tanzania Grass (Panicum maximum Jacq cv. Tanzania-1) Managed in Different Sward Height under Grazing}

\begin{abstract}
The experiment was conducted to evaluate, the forage losses and litter accumulation, in a pasture of Tanzania grass (Panicum maximun Jacq cv. Tanzania) managed in different sward height levels. The studied levels of sward heights (treatments) were: $29.8,32.0,47.1,51.5,57.9,62.7,72.6$ and $80.0 \mathrm{~cm}$, in a completely randomized design and two replications. The litter accumulation rate, litter accumulation and forage losses were similar in all heights. The percentage of senescent forage in the plant canopy was influenced on a quadratic way by the sward height levels. The results show that the litter accumulation and forage losses were high, with average DM of $38.9 \mathrm{~kg} / \mathrm{ha}$.day and $2179 \mathrm{~kg} / \mathrm{ha}$ of DM, respectively. Due to the possibility to reduce the pasture persistence and plant structure deteriorate, it is not recommended to utilize Tanzania grass pastures, in levels sward height near or equal of 20 and $80 \mathrm{~cm}$, under continuous stocking rate.
\end{abstract}

Key Words: senescent forage, litter, continuous stocking, ground cover

\section{Introdução}

Entre as alternativas para melhorar a eficiência dos sistemas de produção de bovinos de corte, está a utilização de gramíneas de estação quente bem adaptadas às condições de meio ambiente da região Noroeste do Paraná, de elevadas produções de matéria seca e de alto valor nutritivo. Entre os cultivares do gênero Panicum maximum, o capim-Tanzânia (Panicum maximum Jacq cv. Tanzania-1), (BARBOSA, 1998; MACHADO et al., 1998), possui as características descritas anteriormente, tornando-se uma forrageira altamente promissora para ser utilizada sob pastejo.
O capim-Tanzânia foi liberado comercialmente no início da década de 90 , porém estudos de manejo dessa gramínea sob pastejo são escassos, principalmente aqueles em que o capim-Tanzânia é submetido a diferentes intensidades de desfolhação e sob lotações contínuas. Por outro lado, sabe-se que as perdas de forragem em gramíneas tropicais cespitosas são elevadas, conforme constataram HILLESHEIM (1987), em capim-elefante. Nas espécies forrageiras de estação fria, sob lotação contínua, também as perdas de forragem são altas, conforme relatos de PARSONS e JOHNSON (1985) e MARASCHIN (1993).

HILLESHEIM (1987) salienta que os estudos

\footnotetext{
${ }^{1}$ Prof. de Forragicultura do Depto de Zootecnia da UEM e Pesquisador do CNPq. Av. Colombo, 3690, CEP 87020-900, Maringá, PR. E.mail: ucecato@uem.br

2 Bolsista PET do curso de Zootecnia - UEM - DZO Av. Colombo, 3690, CEP 87020-900, Maringá, PR.

3 Prof. de Forragicultura do Deto de Zootecnia da UEM. Av. Colombo, 3690, CEP 87020-900, Maringá, PR.

${ }^{4}$ Acadêmicos do curso de Zootecnia da UEM.
} 
conduzidos sobre perdas de forragem têm mostrado formas divergentes e variadas nas condições estudadas, principalmente quando as perdas são quantificadas. Esse autor citou os trabalhos de LE DU et al. (1981), realizados em azevém perene, em que expressaram a fração de material morto em relação à quantidade total de matéria seca, enquanto CHAPMAN et al. (1984) determinaram as perdas de forragem como uma proporção do comprimento total das folhas por perfilho, em espécies de estação fria.

Estudos demonstraram que, em áreas sob pastejo, as perdas de forragem constituem-se em um fator de grande importância, principalmente em razão de parte considerável da matéria seca produzida ser constituída de frações senescentes. Entre os fatores que influenciam a taxa de senescência e as perdas de forragem, estão o manejo da pastagem, a estação de crescimento, a utilização da pastagem realizada sob cortes ou pastejo, a adubação e o sistema de pastejo.

HUGHES (1983) observou que pastagens mantidas com alta oferta de forragem determinam a biomassa de forragem com alta proporção de colmos, acarretando aumento nas perdas e, como consequência, redução na produção de forragem e no rendimento animal e aumento de material morto na pastagem. Por outro lado, a manutenção de quantidades adequadas de forragem disponível acima do solo proporciona maior proteção do solo, atuando na interceptação dos pingos da chuva, reduzindo os riscos de erosão e degradação da pastagem (BROWNING, 1978).

Para o capim-Tanzânia inexistem estudos quantificando as perdas de forragem relativas a níveis de produção de liteira e proporção de forragem senescente na estrutura da planta, embora seja reconhecida sua magnitude em relação à forragem produzida, bem como sua influência na qualidade da forragem disponível para os animais em pastejo.

Portanto, o trabalho foi desenvolvido com o objetivo de avaliar a taxa de acúmulo de liteira, a acumulação de liteira, as perdas de forragem, a porcentagem de forragem senescente e a área de solo descoberto na pastagem de capim-Tanzânia manejado em diferentes alturas sob pastejo com lotação contínua e carga variável.

\section{Material e Métodos}

O experimento foi realizado em uma área da Fazenda Nossa Senhora Aparecida, situada no município de Astorga, região noroeste do Paraná. As coordenadas geográficas, aproximadas, da área experimental são: $51057^{\prime}$ de longitude, $23025^{\prime}$ de latitude e $542 \mathrm{~m}$ de altitude.

A precipitação pluviométrica no período de dezembro de 1998, janeiro, fevereiro, março e abril de 1999 foram 171,$4 ; 222,3 ; 131,1 ; 102,6$ e 115,2 mm, respectivamente.

Segundo CORRÊA (1996), o tipo climático da região é "Cfa", subtropical úmido, mesotérmico com verões quentes e geadas pouco frequentes. O solo do local do experimento é classificado como Latosolo Vermelho-Escuro. O resultado da análise química do solo foi o seguinte: $\mathrm{pH}$ em $\mathrm{H} 2 \mathrm{O}=6,9, \mathrm{Al}+++=$ $0,0 \mathrm{cmol} / \mathrm{dm}^{3}, \mathrm{H}+\mathrm{Al}+++=3,13 \mathrm{cmol} / \mathrm{dm}^{3}$, $\mathrm{Ca}+++\mathrm{Mg}++=7,16 \mathrm{cmol} / \mathrm{dm}^{3}, \mathrm{Ca}++=5,88 \mathrm{cmol} / \mathrm{dm}^{3}$, $\mathrm{K}+=0,60 \mathrm{cmol} / \mathrm{dm}^{3}, \mathrm{P}=3 \mathrm{mg} / \mathrm{dm}^{3} \mathrm{e} \mathrm{C}=15,96 \mathrm{~g} / \mathrm{dm}^{3}$.

A pastagem de capim-Tanzânia (Panicum maximum Jacq cv. Tanzânia-1) foi estabelecida por sementes $($ valor cultural $=28 \%)$ no final do mês de setembro/98 após preparo convencional do solo. Foi dividida em oito unidades experimentais, com áreas que variaram de 1,04 a 1,27 ha, sendo uma área adjacente de cinco hectares destinada aos animais reguladores. A adubação fosfatada e potássica foi realizada a lanço e incorporada por meio de gradagens pouco antes da semeadura. Foram aplicados $180 \mathrm{~kg} / \mathrm{ha}$ de $\mathrm{P}_{2} \mathrm{O}_{5}$ e $60 \mathrm{~kg} /$ ha de $\mathrm{K}_{2} \mathrm{O}$, conforme análise do solo, e as recomendações da COMISSÃO DE FERTILIDADE DO SOLO - RS/SC (1995). A adubação nitrogenada foi fracionada em quatro aplicações, de $40,100,80$ e $30 \mathrm{~kg} / \mathrm{ha}$ de nitrogênio, utilizando-se uréia, aplicada a lanço.

O delineamento experimental foi o completamente casualizado, com duas repetições. Os tratamentos estudados foram quatro níveis de altura do capimTanzânia: 20, 40, 60 e $80 \mathrm{~cm}$. Para a análise estatística, utilizaram-se as alturas das plantas estimadas e registradas ao longo do período experimental, e não as pré-estabelecidas. As alturas observadas foram: $32 \mathrm{~cm}$ para a repetição 1 da altura pretendida de $20 \mathrm{~cm}$ (T20 R1), 29,8 cm (T20 R2), 51,5 cm (T40 R1), $47,1 \mathrm{~cm}$ (T40 R2), 57,9 cm (T60 R1), 62,7 cm (T60 $\mathrm{R} 2), 72,6 \mathrm{~cm}$ (T80 R1) e 80,0 cm (T80 R2).

O método de pastejo utilizado foi o de lotações contínuas com carga variável e ajustes na carga animal a cada 14 dias, de modo a manter os níveis de altura preconizada para cada unidade experimental, conforme MOTT e LUCAS (1952). Os animais utilizados foram novilhos da raça Nelore em fase de recria, com peso médio de $250 \mathrm{~kg}$.

$\mathrm{Na}$ estimativa da altura, considerou-se a extremi- 
dade ou o ponto de curvatura do local em que a fita métrica tocava a lâmina da folha mais alta, a partir do nível do solo. Foram feitas 40 amostragens em cada unidade experimental, com intervalos de 14 dias e, posteriormente, calculada a média da altura em cada piquete.

Para as mensurações das variáveis taxa de acúmulo e acumulação de liteira, perdas de forragem e forragem senescente, no dia 22/02/1999, foram demarcados vinte locais de amostragem, em cada unidade experimental. A determinação do local de cada amostragem foi ao acaso e consistiu de uma

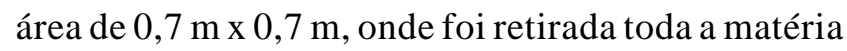
seca de plantas mortas presente acima da superfície do solo (liteira), bem como as porções de tecido de forragem senescente na estrutura das plantas. As coletas da liteira foram realizadas aos 14, 28, 42 e 56 dias, após o início do experimento (22/02/99) em cinco locais, em cada piquete, utilizando-se um quadrado de $0,25 \mathrm{~m}^{2}$. A forragem dos locais amostrados foi cortada rente ao solo e a liteira na superfície do solo foi recolhida. A forragem colhida, posteriormente, foi separada em planta viva ou forragem senescente. As frações de planta viva, forragem senescente e liteira foram secas em estufa com circulação de ar forçado a $600^{\circ} \mathrm{C}$, por 72 horas, para determinação do seu peso seco.

A taxa de acúmulo de liteira diário foi obtida por meio da diferença entre os valores de produção de liteira nos diferentes períodos de colheita, $\mathrm{p} 1$ - p0, p2 - p1, p3 - p2 e p4 - p3 ( p = produção de liteira no período) e dividida pelo número de dias entre cada colheita (14 dias).

A forragem senescente foi obtida pelo percentual de forragem senescente presente na estrutura das plantas. A proporção de perdas de forragem, em relação à quantidade de biomassa presente acima do nível do solo, foi obtida pelas porcentagens de planta viva, forragem senescente e liteira. Os valores percentuais destas frações foram somados e, por cálculo proporcional, foi estimada a variável perdas de forragem. As perdas de forragem, em $\mathrm{kg} / \mathrm{ha}$ de MS, foram quantificadas somando-se a quantidade de forragem senescente na estrutura das plantas na pastagem e de liteira. As áreas de solo descoberto foram estimadas em 14 locais de amostragem, ao acaso, em cada unidade experimental e a intervalos de 28 dias, usando-se um quadrado de $0,25 \mathrm{~m}^{2}$ de área. Esta estimativa foi feita durante o período experimental, de 19/12/1998 a 13/05/1999. A proporção de área com solo descoberto foi estimada conforme metodologia pre- conizada por THOMAS (1980).

As características estudadas foram analisadas estatisticamente por meio de modelos de regressão polinomial, em função dos níveis de altura da forrageira com o auxílio do programa SAS (1985).

\section{Resultados e Discussão}

Durante o período experimental, a carga animal média foi de 4,23; 4,36;4,22 e 4,13 unidades animais/ha, respectivamente, para T20, T40, T60 e T80 cm.

Na Tabela 1 são apresentadas as variáveis taxa de acúmulo e acumulação de liteira, as quais não apresentaram relação significativa $(\mathrm{P}>0,05)$ com os diferentes níveis de altura estudados. A taxa de acúmulo variou de 24 a $89 \mathrm{~kg} / \mathrm{ha} / \mathrm{dia}$ de MS e a acumulação de liteira, de 1351 a $4960 \mathrm{~kg} / \mathrm{ha}$ de MS para as alturas de 72,6 e $80,0 \mathrm{~cm}$, respectivamente. Aparentemente, não há explicação óbvia para a falta de resposta da taxa de acúmulo de liteira com o aumento da altura. No entanto, a variabilidade verificada neste tipo de estimativa (DAVIES, 1993) e o efeito do pisoteio e, principalmente, das condições de umidade que determinam um microclima, favorável ou não, para o aumento da decomposição da liteira por organismos decompositores podem explicar esse fato.

Sabe-se que, à medida que a altura ou biomassa de forragem se eleva, aumenta também a heterogeneidade espacial destes atributos, devido principalmente às diferenças impostas pelos pa-

Tabela 1 - Taxa de acúmulo e acumulação de liteira na pastagem de capim-Tanzânia manejada em diferentes alturas

Table 1 - Litter accumulation rate and litter accumulation in a Tanzania grass pasture managed in different of sward heights

\begin{tabular}{|c|c|c|}
\hline $\begin{array}{l}\text { Altura }(\mathrm{cm}) \\
\text { Height }(\mathrm{cm})\end{array}$ & $\begin{array}{c}\text { Taxa de acúmulo } \\
\text { de liteira } \\
\text { (MS - kg/ha/dia) } \\
\text { Litter } \\
\text { accumulation rate } \\
\text { (DM - kg/ha/day) }\end{array}$ & $\begin{array}{c}\text { Acumulação } \\
\text { de liteira } \\
\text { (MS - kg/ha) } \\
\text { Litter } \\
\text { accumulation } \\
(\text { DM - kg/ha) }\end{array}$ \\
\hline 29,8 & 39 & 2166 \\
\hline 32,0 & 31 & 1730 \\
\hline 47,1 & 28 & 1539 \\
\hline 51,5 & 32 & 1788 \\
\hline 57,9 & 36 & 1990 \\
\hline 62,7 & 34 & 1909 \\
\hline 72,6 & 24 & 1351 \\
\hline 80,0 & 89 & 4960 \\
\hline $\begin{array}{l}\text { Média } \\
\text { Mean }\end{array}$ & 39 & 2179 \\
\hline
\end{tabular}


drões de severidade e pela freqüência de desfolha nos sítios de pastejo.

Ao se analisarem os valores de taxa de acúmulo de liteira, observados neste estudo, verifica-se que há grande quantidade de forragem que se desprende da planta e não é consumida pelos animais, retornando ao ecossistema da pastagem. A taxa média de acúmulo de liteira para todas as alturas avaliadas foi de $39 \mathrm{~kg} / \mathrm{ha} / \mathrm{dia}$ de MS.

Cabe salientar também que existem poucos trabalhos na literatura avaliando taxa de acúmulo de liteira, especialmente aqueles que utilizam animais em pastejo, que poderiam dar mais suporte para as discussões dos resultados obtidos nesta pesquisa.

A produção de liteira que ocorreu nos pastos de capim-Tanzânia é alta. Para um período de 56 dias, a produção média de liteira para todas as alturas analisadas foi de $2179 \mathrm{~kg} / \mathrm{ha}$ de MS (Tabela1).

Essa quantidade de forragem morta tem grande relevância na produção animal, face à contribuição desta fração de liteira no fluxo de matéria seca de ecossistemas com capim-Tanzânia sob pastejo. Os trabalhos publicados por HUNT (1983), SENTHILKUMAR et al. (1992) e KALBURTIJ et al. (1998) mostram a importância dos tecidos de plantas mortas para a reciclagem de nutrientes no solo, nas comunidades de plantas pastejadas. Nesse sentido, SENTHILKUMAR et al. (1992) destacam a atividade da microflora e microfauna na decomposição da liteira, tornando-se essencial para a mineralização da matéria orgânica, nas camadas superficiais do solo.

No presente trabalho pode-se verificar que grande parte da fração liteira foi de folhas mortas. A participação dos perfilhos em que o meristema apical foi decapitado e daqueles dilacerados pelo pisoteio animal, principalmente nas menores alturas, apresentou baixa contribuição para a taxa de acúmulo de liteira, em relação à proporção de folhas mortas.

Os valores estimados de perdas de forragem, expressos em porcentagem do resíduo e em $\mathrm{kg} / \mathrm{ha}$ de MS, são apresentados na Tabela 2. Nos diferentes níveis de altura estudados, não houve incremento $(\mathrm{P}>0,05)$ nas perdas de forragem, quando quantificadas em porcentagem da matéria seca acima da superfície do solo ou em $\mathrm{kg} / \mathrm{ha}$ de MS.

As perdas de forragem variaram de $30,7 \%$ na altura do capim-Tanzânia de $72,6 \mathrm{~cm}$ a $47,1 \%$ na altura de $51,5 \mathrm{~cm}$.

A falta de significância entre os níveis de altura e as perdas de forragem, expressas em bases percentuais, está associada, em parte, ao comporta-
Tabela 2 - Perdas de forragem, expressas em porcentagem da disponibilidade e em $\mathrm{kg}$ de matéria seca/ha, na pastagem de capimTanzânia manejada em diferentes alturas

Table 2 - Losses of forage, in percentage of forage mass level and expressed in $\mathrm{kg} / \mathrm{ha}$ of DM of dry matter/ha, in a Tanzania grass pasture managed in different sward heights

\begin{tabular}{lcc}
\hline $\begin{array}{l}\text { Altura }(\mathrm{cm}) \\
\text { Height }(\mathrm{cm})\end{array}$ & $\begin{array}{c}\text { Perdas de } \\
\text { forragem }(\%) \\
\text { Forage losses }(\%)\end{array}$ & $\begin{array}{c}\text { Perdas de } \\
\text { forragem } \\
\text { (MS-kg/ha) } \\
\text { Forage losses } \\
(\text { DM-kg/ha) }\end{array}$ \\
\hline 29,8 & 43,7 & 2137 \\
32,0 & 40,1 & 1975 \\
47,1 & 41,9 & 2011 \\
51,5 & 47,1 & 1994 \\
57,9 & 45,7 & 2345 \\
62,7 & 41,4 & 1924 \\
72,6 & 30,7 & 1734 \\
80,0 & 33,5 & 3129 \\
\hline Média & 40,5 & 2156 \\
Mean & & \\
\hline
\end{tabular}

mento da variável proporção de forragem senescente (Figura 1), pois eram esperadas maiores perdas de forragem onde a pastagem era mais alta.

As perdas de forragem, para o período de 56 dias de avaliação na média dos quatro tratamentos, foi de $2156 \mathrm{~kg} /$ ha de MS (Tabela 2), sendo consideráveis e inferiores às relatadas por SISTI et al. (1999), que registraram $3724 \mathrm{~kg} / \mathrm{ha}$ de MS em pastagens de capim-Mombaça (Panicum maximum Jacq. cv. Mombaça), avaliadas durante 300 dias de crescimento.

Assim, pode-se afirmar que os ecossistemas de capim-Tanzânia pastejados se caracterizam por apresentar grande quantidade de forragem disponível. Contudo, ficou evidenciado que grande parte desta é formada por material senescente, que está continuamente retornando à superfície do solo da pastagem.

De um ponto de vista prático, objetivando o manejo de pastagens de capim-Tanzânia sob lotações contínuas, deve-se evitar alturas de resíduo pós-pastejo muito altos ou muito baixos. Nas menores alturas de resíduo $(20 \mathrm{~cm})$, com o passar dos anos, a pastagem tenderia a se degradar e, nas maiores alturas $(80 \mathrm{~cm})$, haveria alongamento dos entre-nós dos colmos e redução da relação folha/colmo e dos teores de proteína bruta e digestibilidade da matéria seca, determinando a queda de qualidade da forra- 
gem disponível para os animais em pastejo.

A porcentagem de forragem senescente apresentou relação quadrática $(\mathrm{P}<0,013)$ com os níveis de altura avaliados (Figura 1). O percentual de forragem senescente elevou-se, à medida que aumentou o nível de altura de forrageira, até certo ponto, a partir do qual houve decréscimo. Esse comportamento pode ser atribuído, principalmente, às diferenças nas proporções de peso da matéria seca, entre os componentes estruturais folhas e colmos. Os colmos amarelecidos foram considerados fisiologicamente ativos, fazendo, portanto, parte da porção planta viva. Em decorrência deste procedimento, à medida que se elevou a altura do pasto acima de $50 \mathrm{~cm}$, verificaram-se aumento na participação dos colmos e redução na porcentagem de forragem senescente no resíduo de matéria seca/ha. Isto ocorreu em função de os colmos dos perfilhos de capim-Tanzânia possuírem maior peso específico que as lâminas das folhas, principalmente os colmos de maior idade e lignificados, com os entre-nós já alongados.

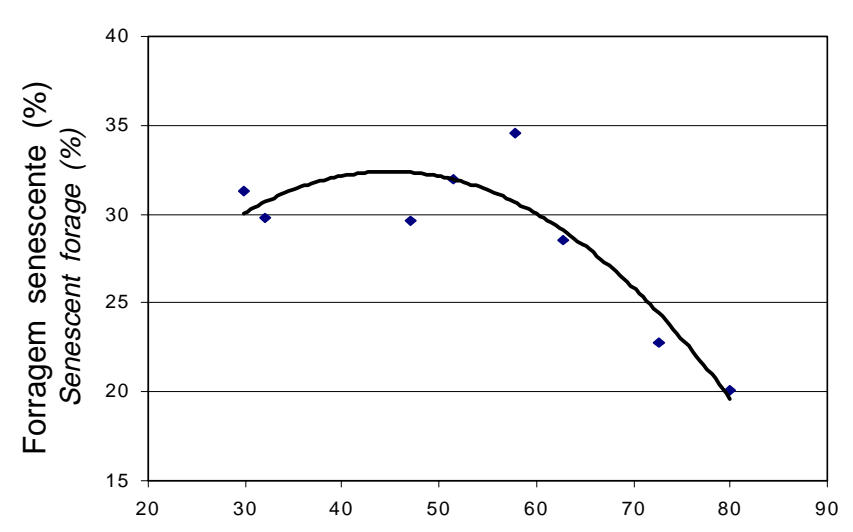

Altura (cm)

Height $(\mathrm{cm})$

Figura 1 - Forragem senescente (\%) na estrutura das plantas de capim-Tanzânia em direrentes alturas.

Figure 1 - Senescent forage (\%) in plant structure of Tanzânia grass in different sward heights.
Diversos estudos têm analisado a participação da porcentagem de forragem senescente na estrutura das plantas de comunidades pastejadas. No experimento conduzido por MOOJEN (1991), a porcentagem de forragem senescente aumentou linearmente com a diminuição da pressão de pastejo e elevação do nível de resíduo de matéria seca/ha. Também outros estudos demonstram acréscimo da proporção de material senescente com o aumento da disponibilidade de forragem (PIZZIO et al., 1986) ou da altura da pastagem (CARNEVALLI et al., 1999), que contrastam com o observado neste estudo.

Os valores estimados de área de solo descoberto, durante os 145 dias de pastejo, estão apresentados na Tabela 3 , sendo semelhantes $(\mathrm{P}>0,05)$ nos tratamentos. A área de solo descoberto oscilou de $2,4 \%$, na altura de $47,1 \mathrm{~cm}$, a $15,5 \%$ na altura de $57,9 \mathrm{~cm}$.

Estes resultados de solo descoberto, relativamente baixos, foram atribuídos aos bons níveis de biomassa de forragem mantidos acima do nível do solo, em todas as unidades experimentais. Em média, as porcentagens de solo descoberto foram muito baixas, ao longo do período experimental. Somente nas alturas de $29,8 \mathrm{~cm}$ e $57,9 \mathrm{~cm}$ ocorreram valores pouco superiores a $10 \%$ de solo descoberto.

Uma das características de pastagens de capim-Tanzânia é a formação de touceiras que são circundadas por áreas descobertas, onde os animais se deslocam. Foram nestes locais que se observaram as poucas área de solo não cobertas pelas folhas dos perfílhos do capim-Tanzânia, nas menores alturas. Nestas a maior porcentagem de solo descoberto foi consequência da maior pressão de pastejo, que reduziu o diâmetro das touceiras e a produção de matéria seca por área. No entanto, as áreas de solo descoberto, no presente trabalho, apresentaram grande quantidade de material morto acima do nível do solo (Tabela 1).

É interessante considerar que as áreas utilizadas sob pastejo, com baixas proporções de solo sem cobertura vegetal, mantêm a integridade do solo e minimizam os riscos de erosão, assegurando a persistência da pastagem e a sustentabilidade da produção de forragem. 
CECATO et al.

Tabela 3 - Área de solo descoberto (\%) em uma pastagem de capim-Tanzânia manejada em diferentes alturas, por data de amostragem

Table 3 - Uncovered soil area (\%) in Tanzania grass pasture managed in different levels of sward height by sampling dates

\begin{tabular}{|c|c|c|c|c|c|c|}
\hline \multirow[b]{2}{*}{$\begin{array}{l}\text { Altura }(\mathrm{cm}) \\
\text { Height }(\mathrm{cm})\end{array}$} & \multicolumn{5}{|c|}{$\begin{array}{c}\text { Data de amostragem } \\
\text { Sampling time }\end{array}$} & \multirow[b]{2}{*}{$\begin{array}{l}\text { Média } \\
\text { Mean }\end{array}$} \\
\hline & $18 / 12 / 98$ & 02/02/99 & $01 / 03 / 99$ & 08/04/99 & $22 / 05 / 99$ & \\
\hline 29,8 & 1,7 & 32,0 & 5,1 & 13,5 & 21,9 & 15,5 \\
\hline 32,0 & 0,1 & 33,3 & 3,7 & 9,2 & 12,5 & 8,4 \\
\hline 47,1 & 0,0 & 7,8 & 1,7 & 0,6 & 3,6 & 2,4 \\
\hline 51,5 & 0,0 & 13,5 & 7,2 & 1,8 & 2,0 & 4,0 \\
\hline 57,9 & 10,4 & 21,1 & 10,5 & 2,5 & 4,9 & 10,1 \\
\hline 62,7 & 0,5 & 13,4 & 1,9 & 4,2 & 4,7 & 3,5 \\
\hline 72,6 & 0,0 & 17,7 & 0,5 & 0,5 & 4,4 & 4,3 \\
\hline 80,0 & 0,0 & 8,3 & 20,3 & 0,0 & 1,4 & 4,0 \\
\hline
\end{tabular}

\section{Conclusões}

As diferentes alturas do capim-Tanzânia na pastagem não influenciaram a taxa de acúmulo e acumulação de liteira, perdas de forragem e a área de solo descoberto. A porcentagem de material senescente na estrutura das plantas foi maior nas alturas intermediárias.

No capim-Tanzânia manejado em diferentes alturas, sob lotação variável, as perdas de forragem, em termos de liteira e material senescente, foram elevadas e a área de solo descoberta, reduzida.

\section{Agradecimento}

Ao Sr. William Watfe, pelos recursos financeiros destinados à pesquisa, bem como pelo uso da área experimental e das instalações da fazenda Nossa Senhora de Aparecida, e à Tortuga S.A., pelo fornecimento de sal mineral.

\section{Referências Bibliográficas}

BARBOSA,M.A.F. Influência da adubação nitrogenada e das frequências de corte na produção e nas variáveis morfogênicas do Capim Mombaça (Panicum maximum Jacq) cv. Mombaça. Maringá, PR: UEM, 1998. 53 p. Dissertação (Mestrado em Zootecnia) - Universidade Estadual de Maringá, 1998.

BROWNING, G.M. 1978. Forrajes: La ciencia de la agricultura basada en producion de pastos. In: HEAT, M.E., BARNES, R.F., METECALFE, D.S. (Eds.) Los forrages y la conservacion del suelo. Ames, Iowa: State University Press. p.47-58.

CARNEVALLI,R.A, DA SILVA, S.C., PEDREIRA,C.G.S et al. Pasture and animal responses of tifton 85 swards grazed by sheep under continuous stocking. In: PROCEEDINGS OF
INTERNATIONAL SYMPOSIUM “GRASSLAND ECOPHYSIOLOGY AND GRANZING ECOLOGY”, 1999, Curitiba. Procedings... Curitiba: UFPR, 1999. p.357-361.

COMISSÃO DE FERTILIDADE DO SOLO - RS-SC. 1995. Recomendações de adubação e calagem para os Estados do Rio Grande do Sul e Santa Catarina. 3.ed. Passo Fundo: SBCS-EMBRAPA-CNPT. 223p.

CORRÊA, A.R. Forrageiras: aptidão climática do Estado do Paraná. 1996. In: MONTEIRO, A.L.G., MORAES, A., CORRÊA, E.A.S. et al. Forragicultura no Paraná. Londrina: Comissão Paranaense de Avaliação de Forrageiras. p.15-22.

DAVIES, A. 1993. Tissue turnover in the sward. In: DAVIES, A., BAKER, R.D., GRANT, S.A. et al. (Eds.) Sward measurement handbook. Reading: Britsh Grassland Society. 2.ed.p.183-215.

HILLESHEIM, A. Fatores que afetam o consumo e perdas de capim- elefante (Penissetum purpureum, Schum) sob pastejo. Piracicaba: ESALQ, 1987. 94p. Dissertação (Mestrado em Zootecnia) - Escola Superior de Agricultura "Luis de Queiroz", 1987.

HUGHES, T.P. 1983. Grazing intake. Farmers Handbook. Lincoln College. Animal Industries Workshop. p.17-21.

HUNT,W.F. 1983. Nitrogen cycling through senescent leaves and litter in swards of Ruanuui and Nui ryegrass with high and low nitrogen inputs. New Zealand of Agricultural Reseach, 26:461-471.

KALBURTJI, K.L., MAMOLOS, A.P., KOSTOPOULOU, S.K. et al. 1998. Litter dynamics of Dactylis glomerata and Vicia villosa with respect to climatic and soil characteristics. Grass and Forage Science, 53:225-232.

MACHADO, A.O, CECATO, U., MIRA, R.T. et al. 1998. Avaliação da composição química e digestibilidade in vitro da matéria seca de cultivares e acessos de Panicum maximum Jacq. sob duas alturas de corte. R. Bras. Zootec., 27:(6)1057-1063.

MARASCHIN, G.E. Perdas de forragem sob pastejo. In: SIMPÓSIO SOBRE ECOSSISTEMAS DE PASTAGEM, 2, 1993, Jaboticabal. Anais... Jaboticabal: Faculdade de Ciências Agrárias e Veterinárias, 1993. p.166-190.

MOOJEN, E.L. Dinâmica e potencial produtivo de uma pastagem natural submetida a níveis de pressão de pastejo, épocas de diferimento e níveis de adubação. Porto Alegre: UFRGS, 1991. 192p. Tese (Doutorado em Zootecnia) - Universidade Federal do Rio Grande do Sul, 1991. 
Rev. bras. zootec.

MOTT, G.O., LUCAS, H.L. 1952. The desing conduct and interpretation of grazing trials on cultivated and improved pastures. In: INTERNATIONAL GRASSLAND CONGRESS, 6, State College, 1952. Proceedings... Pensylvania, State College Press, 1952. p.1380-5.

PARSONS, A.J., JOHNSON, I.R. The physiology of grass growth under grazing. In: FRAME, J. (Ed.) Grazing. Hurley: British Grassland Society, 1985. p.3-13.

PIZZIO, R.M., BENITEZ, C.A., FERNANDEZ, J.G. et al. 1986. Mejoramiento y carga animal en uma pradera natural del centro de la Provincia de Corrientes. I. Disponibilidad de Foraje. Revista Argentina de Producion, 6 (7-8):437-449.

SAS. Statistics Analysis System. 6 ed. Cary. NC: SAS Institute INC: USA, 1985. 429p.

SENTHILKUMAR, K., UDAYAN,K., MANIAN, S. et al. 1992. Rate of litter decomposition in a tropical grassland dominated by Cibopogon caesius in Southen India. Trop. Grassland, 26:235-242.
SISTI, C.P.J., HERLING, V.R., LUZ, P.H.C. et al. Efeitos da oferta de forragem e de períodos de descanso sobre a produção, perdas e resíduo de matéria seca do Capim Mombaça (Panicum maximum Jacq.) In: REUNIÃO ANUAL DA SOCIEDADE BRASILEIRA DEZOOTECNIA, 36, 1999, Porto Alegre. Anais... Porto Alegre: SBZ, 1999. p.12.

THOMAS, H. Terminology and definitions in studies of graasland plants. 1980. Grass and Forage Sci., 35:13-23.

Recebido em: $14 / 03 / 00$

Aceito em: 09/10/00 